1 Bernard RS. Paraduodenal hernias. Surg Gynaecol Obstet 1981;152:99-110

Williams WH. The surgical management of paraduodenal hernia. Ann Surg 1968;108: ment of

3 Meyers MA. Paraduodenal hernias: radiologic and arteriographic diagnosis. Radiology 1970;95:29-37.

4 Tirel M. Left paraduodenal hernia. Br $\mathcal{F}$ Surg 1982;69. 114.

5 Filtzer $H$, Sedwick CE. Strangulated paraduodenal hernia: a case report. Surg Clin North Am 1973;53: $371-4$

6 Wilwerth BM, Zollinger RM, Izand RJ. Congenital mesocolic (paraduodenal) hernia: embryologic basis of repair. Am f Surg 1974;128:358-61.

7 Lee TKY, Voon FCT, Chow KW, et al. Unusual variant of right paraduodenal hernia. Aust NZ f Surg 1990;60: 483-5.

8 Freud H, Berlatzky Y. Small paraduodenal hernias. Arch Surg 1977;112:1180-3.
9 Ghahreman GG. Internal abdominal hernias. Surg Clin North Am 1984;64:393-401.

10 Newsom BD, Kukora JS. (1986) Congenital and acquired hernias: unusual causes of small bowel obstruction. $A m$ f Surg 1986;152:279-85.

11 Brigham RA, Saunders JR, Harmon JW, et al. Paraduodenal hernia: diagnosis and management. Surgery 1984;96: 498-502.

12 Olazabal A, Guasch I, Casas D. Case report: CT diagnosis of non-obstructive left paraduodenal hernia. Clin Radiol 1992;46:288-9.

13 Turley K. Right paraduodenal hernia. A source of chronic abdominal pain in the adult. Arch Surg 1979;114: 1072-4.

14 Dengler WC, Reddy PP. Right paraduodenal hernia in childhood. A case report. $f$ Pediatr Surg 1989;24: 1153-4.

15 Suflan S, Matsumoto T. Intestinal obstruction. Am ₹ Surg 1975;130:9-14.

\title{
Respiratory compromise: a rare complication of transcutaneous electrical nerve stimulation for angina pectoris
}

\author{
C J Mann
}

\begin{abstract}
Electrical stimulation of any muscle group may produce tetany. If the intercostal muscles are involved this may lead to respiratory embarrasment. A case is presented in which transcutaneous electrical nerve stimulation (TENS) treatment for angina pectoris resulted in respiratory arrest.
\end{abstract}

( $\mathcal{F}$ Accid Emerg Med 1996;13:68-69)

Key terms: transcutaneous electrical nerve stimulation; respiratory arrest.

Electrical neurostimulation as an analgesic technique has been used succesfully for many years particularly in obstetrics. More recently it has been used in patients with severe unstable angina refractory to pharmocological therapy. ${ }^{1-3}$ One potential hazard is highlighted by this case.

\section{Case report}

A 70 year old man with a long history of ischaemic heart disease suffered an attack of angina pectoris during ambulance transport to a routine cardiology outpatient appointment. One year earlier a transcutaneous nerve stimulator system (TENS) had been fitted, with stimulating electrodes placed anteroposteriorly across the chest wall to control the pain of his unstable angina The episode of chest pain in the ambulance had been very severe and he had increased the TENS current to maximum $(50 \mathrm{~mA})$. The ambulance crew brought him directly to the accident and emergency department.

On examination in the resuscitation room the patient was conscious but unable to speak. The respiratory rate was $25 / \mathrm{min}$ with very shallow breaths. There was central cyanosis. On auscultation breath sounds were normal although air entry was minimal. The pulse was $65 / \mathrm{min}$ of good volume and regular. Blood pressure was $140 / 85 \mathrm{~mm} \mathrm{Hg}$.

High flow oxygen was given from a reservoir system with no clinical benefit. It was not possible to record an electrocardiograph as discharges from the TENS machine produced considerable electrical interference. The patient deteriorated and chest wall movement virtually ceased. The respiratory pattern was that of tetanic paralysis with incoordinated sustained muscular contraction.

The TENS electrodes were removed. Immediately the patient exhaled and was able to respire with much greater movement of the chest wall. Within a few minutes the respiratory pattern had returned to normal. On questioning he was pain-free. The dyspnoea subsequently resolved completely. An ECG showed no changes from previous electrocardiographs and after attending the outpatient clinic the patient was discharged home.

\section{Discussion}

The lack of familiarity with neurostimulators for the treatment of angina pectoris meant that the medical staff treating this patient were at a disadvantage in determining the cause of the acute deterioration. There are no previous reports of similar problems with TENS systems, although subjective symptoms of difficulty in breathing are not uncommon (Mannheimer C, personal communication). This case shows the potential for more serious complications with neurostimulators.

1 Mannheimer C, Carlsson C-A, Ericson K, Vedin A Wiihelmson C. Transcutaneous electrical nerve stimulation in severe angina pectoris. Eur Heart $\mathcal{f} 1982 ; 3$ 297-302.

2 West $P$, Colquhoun $D$. TENS in refractory angina pectoris Med $\mathcal{F}$ A ust 1993;158:488-9.

3 Sanderson J. Electrical neurostimulators for pain relief in angina. Br Heart F 1990;63:141-3. 